\title{
Técnicas de Modulação QAM-4 Para Canais Não-Lineares
}

\author{
Ernesto L. Pinto e joão Célio B. Brandão
}

\begin{abstract}
Oiversas têcnicas de modulaçăo quaternárias apresentadas em publicaçčes recentes para aplicaçōes a canais nåo lineares săo analisadas atravês do modelo QAM (Modulação de Amplitude em Quadratura). Para este tipo de canal deseja-se que o sinal modulado, alêm de elevada eficiência na ocupaçāo do espectro de freqüências, também apresente pouca variaçăo de envoltória. Estas propriedades săo também discutidas aqui.
\end{abstract}

\section{Introdução}

Importantes sistemas de comunicações, como os sistemas via satélite, se caracterizam pela necessidade de se utilizar amplificadores operando na regiâo não linear a fim de maximizar a eficiência no uso da potência disponível. Estes amplificadores se constituem numa fonte adicional de degradação no desempenho do sistema, além da limitação da faixa dé freqüericias e do ruido [1].

Quando o canal de transmissäo pode ser modelado como canal passa-faixa linear com ruído aditivo gaussiano na entrada do receptor, pode-se obter probabilidade de erro minima, definindo os filtres de transmissão e recepção de modo que se obtenha na entrada do receptor, pulsos casados com o filtro de recepção e que os pulsos na saida deste filtro satisfaçami no Primeiro Critério de Nyquist [2]. Haverido uma näo linearidade no cana!, não é possivel utilizar o Primeiro Critério de Nyquist para definição de um sistema de transmissăo ótimo e o desempenho do sistema melhora se os sinais modula. dos têm pouca ou nenhuma variaçấo de envoltória [a]. Apesar disso, a nodulação QPSK ("Quadrature Phase Shift Keying"), cujo sinai iltrado apresenta variaçôes intensas de envoitória, tem sido geraimente usadá eni siste. mas de comunicações via satélite [1] .

$\therefore$. Finto \& Professor do Insittuto Milhtar de Engenharia (MAE), Praça Gal Tibücio, $30_{\text {, }}$ 2020, Rio de Janeiro, RJ.

…B. Erandzo é Professor do Centro ds Estudos en Teleconunicaçöes da PUC/Ric, 22453, Iic de vaneiro, RJ. 
Nos últimos anos, no entanto, várias técnicas de modulação têm sido apresentadas como alternativas à modulação QPSK para aplicaçōes a canais nāo lineares [3] - [10] . Estas técnicas podem ser derivadas do QPSK introduzindo-se um desalinhamento de meio intervalo de símbolo entre os sinais de banda básica do modulador e variando-se a forma de pulso de transmissão. Assim, as modulaçōes resultantes podem utilizar a mesma estrutura de modulador e demodulador que a modulação QPSK, uma vez que todas elas podem ser vistas como modulações QAM ("Quadrature Amplitude Modulation") [11] . Neste trabalho, utiliza-se o modelo de sinal QAM para a apresentação e discussão das propriedades de várias destas técnicas, procurando-se avaliálas quanto à ocupação do espectro de freqüências e à variação na envoltória do sinal modulado.

Este artigo está organizado da seguinte maneira: na Seção 2 é apresentado - modelo de sinal QAM e são discutidos alguns aspectos da transmissão deste tipo de sinal em canal linear. Na Seção 3 são discutidas algumas limitaçōes de desempenho impostas pela presença de uma não linearidade no canal. $\mathrm{Na}$ Seção 4 são apresentadas várias técnicas de modulação QAM-4 (QAM quaternária), e discutidas as suas características de envoltória e ocupação espectral. $\mathrm{Na}$ Seção 5 são apresentados os comentários finais e as principais conclusões do trabalho.

\section{Transmissão de Sinais QAM·4 em Canais Lineares}

Um sinal $m(t)$ com modulação QAM quaternária pode ser definido matematicamerite por

$$
\begin{aligned}
m(t)=A \sum_{k}\left[a_{2 k} p_{c}(t-k T) \cos \left(2 \pi f_{c} t-\phi_{0}\right)-\right. & \\
& \left.-a_{2 k+1} p_{s}(t-k T) \operatorname{sen}\left(2 \pi f_{c} t-\phi_{0}\right)\right]
\end{aligned}
$$

onde $A$ é a amplitude da portadora, $\left\{a_{k}\right\}, k=\ldots,-1,0,1, \ldots$ é a seqüência binária de informação, $a_{k}= \pm 1 ; p_{c}(t)$ e $p_{S}(t)$ são os pulsos de baixa freqüência dos canais em fase e quadratura, respectivamente; $T$ é o inverso da taxa de simbolos; $f_{c}$ é a freqüência da portadora e $\phi_{0}$ uma fase constante e arbitrária que pode ser suposta nula quando se trata de sistemas com recepção coerente.

O esquema básico de um transmissor QAM-4 é mostrado na Fig. 1, onde $\delta$ (t) representa a função impulso. A seqüência de informação é chaveada entre os canais em fase e quadratura e é usada para modular em amplitude 
os pulsos de banda básica $p_{C}(t)$ e $p_{S}(t)$. Os sinais resultantes modulam em amplitude as portadoras em fase e quadratura. A composição (adição) das portadoras moduladas produz o sinal QAM-4.

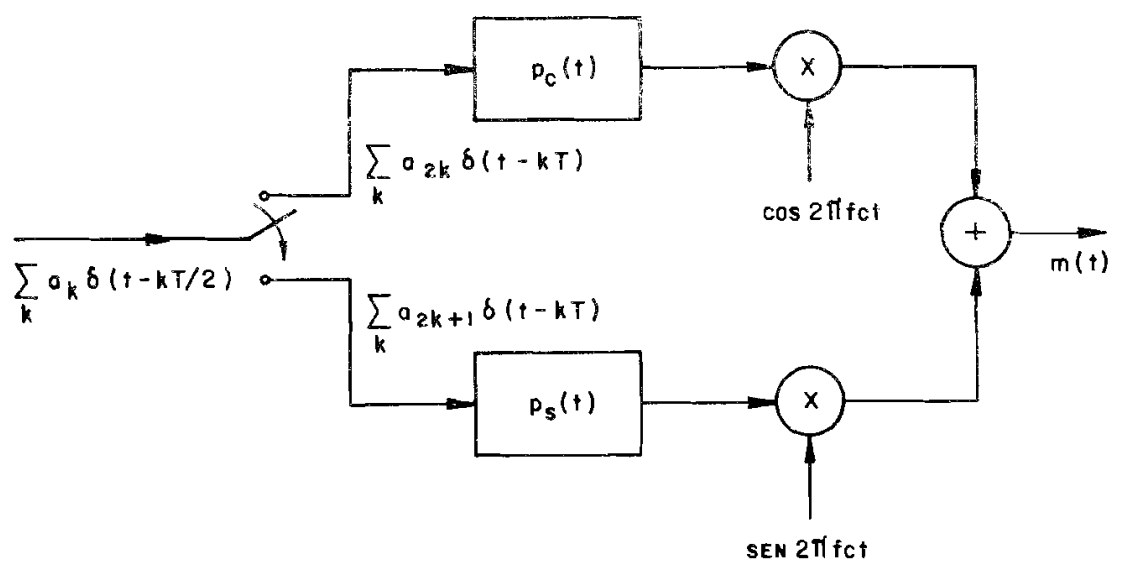

Figura 1. Esquema de um transmissor QAM-4.

A envoltória complexa do sinal $Q A M-4$ em (1), relativa à freqüência $f_{C}$, é dada por

$$
m(t)=A \sum_{k}\left[a_{2 k} p_{c}(t-k T)+j a_{2 k+1} p_{s}(t-k T)\right]
$$

Supondo que a seqüência de informação $\left\{a_{k}\right\}$ é tal que $P\left(a_{k}=+1\right)=$ $P\left(a_{k}=-1\right)$ para todo $k$ e $E\left[a_{i} . a_{i j}\right]=0$ para todo $i, j$ com $i \neq j$, resulta que a densidade espectral de potencia de $\mathbf{m}(\mathrm{t})$ é dada por

$$
S_{m}(f)=\frac{A^{2}}{T}\left[\left|P_{c}(f)\right|^{2}+\left|P_{S}(f)\right|^{2}\right]
$$

onde $P_{C}(f)$ e $P_{S}(f)$ são transformadas de Fourier dos pulsos de baixa freqüência $p_{C}(t)$ e $p_{S}(t)$ [12] .

Como em geral os pulsos $p_{c}(t)$ e $p_{S}(t)$ são idênticos, a menos de um deslocamento no tempo, tem-se

$$
S_{m}(f)=\frac{2 A^{2}}{T}\left|P_{c}(f)\right|^{2}=\frac{2 A^{2}}{T}\left|P_{S}(f)\right|^{2}
$$

A eficiência espectral de sinais modulados é comumente caracterizada através da quantidade $\mathrm{Pm}(B)$ que expressa a fraçāo de potência fora de uma faixa de largura $B$ centrada em $f_{C}$. No caso do espectro dado por (4) tem-se 


$$
P_{m}(B)=1-\left\langle\int_{-B / 2}^{B / 2}\left|P_{c}(f)\right|^{2} d f / \int_{-\infty}^{\infty}\left|P_{c}(f)\right|^{2} d f\right)
$$

Considerando-se a passagem do sinal QAM-4 por um filtro cuja resposta impulsional tem envoltória complexa $\mathbf{h}(\mathbf{t})$, a envoltória do sinal na saída do filtro será dada por [13]

$$
x(t)=\frac{1}{2} m(t) * h(t)
$$

Se a função de transferência $H(\mathfrak{f})$ deste filtro for simetrica em relação à freqüência $f_{C}$, ou seja, se

$$
H\left(f-f_{c}\right)=H^{*}\left(f+f_{c}\right)
$$

então a envoltória $h(t)$ será real [14] e pode ser dada por $h(t)$. Nesta condição a substituição de (2) em (6) resulta em

$$
x(t)=\frac{A}{2}-\sum_{k}\left[a_{2 k} p_{1}(t-k T)+j a_{2 k+1} p_{2}(t-k T)\right]
$$

onde

$$
\begin{aligned}
& p_{1}(t)=p_{c}(t) * h(t) \\
& p_{2}(t)=p_{s}(t) * h(t)
\end{aligned}
$$

Assim sendo, o efeito de uma filtragem simétrica sobre o sinal QAM (quaternário no caso) será apenas a alteração da forma dos pulsos de baixa freqüência. Quando o filtro não é simétrico, há transferência de energia entre os sinais de baixa freqüência dos canais em fase e quadratura.

O esquema de um receptor QAM coerente é mostrado na Fig. 2. É feito um batimento do sinal recebido $r(t)$ com as portadoras em fase $\varepsilon$ quadratura, seguido de filtragem passa-baixa, amostragem e decisão em cada um dos sanais.

Quando o canai é linear, com funçăo de transferência simétrica e ruído aditivo gaussiano branco na entrada do receptor, o esquema da Fig. 2 pode ser ótimo, no sentido de minimizar a probabilidade de erro na deteção. Para tanto, é necessário que os illtros FPB1 e FPB2 sejam casados com os 


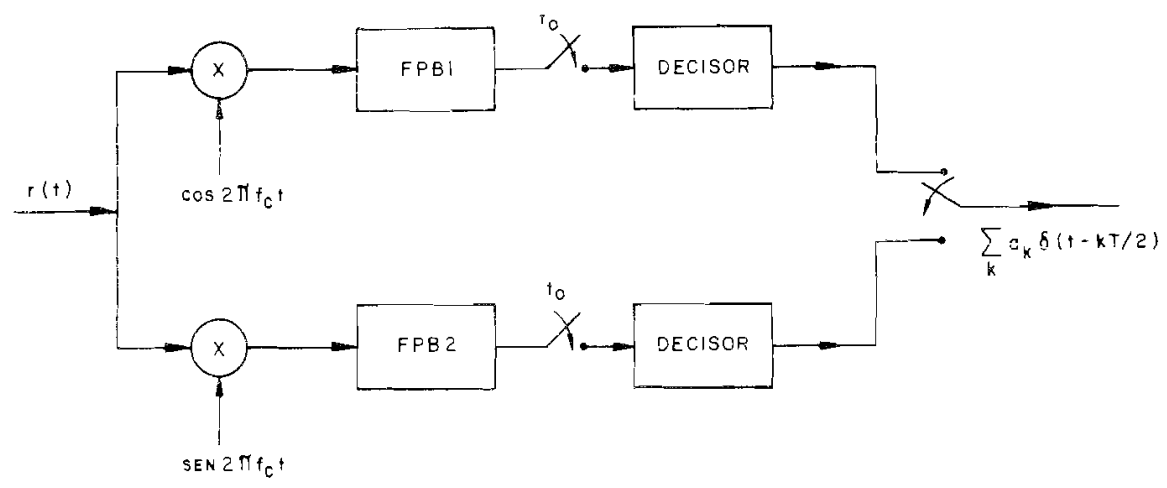

Figura 2. Receptor QAM coerente.

puisos de baixa freqüencia do sinal na entrada do receptor e que os pulsos resultantes na entrada dos amostradores satisfaçam ao Primeiro Critério de Nyquist [2]. Desde que o canal tenha característica plana, isto leva ao uso de filtros de transmissão e recepção do tipo raiz quadrada de consseno levantado. Conveniências de ordem prática, no entanto, podem levar ao uso de outros tipos de filtros.

\section{Transmissão em Canais Não-Lineares}

Para efeito de análise de desempenho dos sistemas de comunicações, os amplificadores não lineares presentes em diversos canais de interesse são geralmente modelados como não linearidades sem memória. Quando apenas uma portadora modulada e limitada em faixa passa pela não linearidade sem memória, são introduzidas modulações de amplitude e fase nesta portado$\mathrm{ra}$, em função das variações de sua própria envoltória. Quando mais de uma portadora têm acesso simultâneo à não linearidade, ocorre também - fenômeno da intermodulação. Este trabalho restringe-se à consideração do primeiro caso.

Seja $x(t)$ uma portadora modulada, de faixa limitada, expressa por

$$
f(t)=a(t) \cos \left[2 \pi f_{c} t+\phi(t)\right]
$$

Considerando sua passagem por uma năo linearidade sem memória, a saida sorrespondente será dada por [1]

$$
f(t)=f(a(t)) \cos \left[2 \pi t_{c} t+\phi(t)+g(a(t))\right]
$$

Tevista da Sociedade Brasileira de Telecomunicações iolume 2. No 1, dezembro 1987. 
Assim, a saída será uma versão da entrada distorcida em amplitude e fase, a não ser que a envoltória do sinal de entrada seja constante. As funções $f(\cdot)$ e $g(\cdot)$ caracterizam as modulaçōes de amplitude e fase produzidas pela não linearidade, denominadas conversão $A M / A M$ e $A M / F M$, respectivamente. Estas funções são geralmente apresentadas através de curvas experimentais de potência de saída versus potência de entrada e fase de saída versus potência de entrada. Os valores de potência são normalizados em relação ao ponto de saturação do dispositivo e dados pelo recuo ("backoff") de entrada e pelo recuo de saida.

$\mathrm{Na}$ transmissão QAM, a presença da nāo linearidade impossibilita a eliminação da interferência entre símbolos através do uso do Primeiro Critério de Nyquist. Por outro lado, a passagem de um sinal de faixa limitada pela não linearidade provoca o espalhamento do espectro de potência deste sinal, produzindo interferência sobre canais adjacentes.

Assim sendo, o desempenho do sistema de transmissão pode se degradar severamente e se torna de grande interesse a obtenção de técnicas de modulação que sejam pouco sensiveis aos efeitos das não linearidades. Idealmente, um sinal modulado, limitado em faixa à largura do canal e com envoltoria constante, seria insensivel às degradações produzidas pelas não linearidades. É portanto de grande interesse a investigação de técnicas de modulação que produzam sinais com pouca variação de envoltória e elevada eficiência espectral. Devido à simplicidade de implementação dos transmissores e receptores, as técnicas QAM-4 podem ainda oferecer vantagens adicionais e são um objeto natural de pesquisa de novos sistemas de modulação.

\section{Técnicas QAM-4 Especificas}

Conforme se pode observar nas seções 2 e 3 as características de envoltória e ocupação espectral dos sinais QAM-4, e, consequentemente, a sua maior ou menor adequação à transmissão em canais não lineares ficam caracterizadas pela definição dos pulsos de banda básica $p_{C}(t)$ e $p_{S}(t)$ em (1). São apresentadas em seguida diversas técnicas QAM-4 através da definição destes pulsos e da discussão de algumas propriedades decorrentes desta definição.

\subsection{QPSK, OQPSK e MSK}

Na modulação QPSK ("Quadrature Phase Shift Keying") os pulsos de banda básica são dados por

$$
p_{c}(t)=p_{s}(t)=\operatorname{ret}_{T}(t)
$$


onde ret $_{\mathrm{T}}(\mathrm{t})$ é a função pulso retangular dada por

$\operatorname{ret}_{\tau}(t)=\left\{\begin{array}{l}1, \text { se }|t| \leqslant \tau / 2 \\ 0, \text { se }|t|>\tau / 2\end{array}\right.$

A envoltória complexa do sinal QPSK, obtida pela substituição de (11) em (2). pode ser dada por

$m(t)=A \sqrt{2} \sum_{k} \exp \left(j \phi_{k}\right) r e t_{T}(t-k T)$

onde

$\phi_{k}=\operatorname{tg}^{-1}\left(a_{2 k+1} / a_{2 k}\right)$

O módulo desta envoltória complexa ou simplesmente a envoltória é constante, podendo apresentar variações instantâneas de fase no início de cada intervalo de símbolo. Estas transiçōes, dependendo dos bits de informação de cada canal, serão de $\pi / 2$ ou $\pi$ radianos, como é mostrado na Fig.3(a).
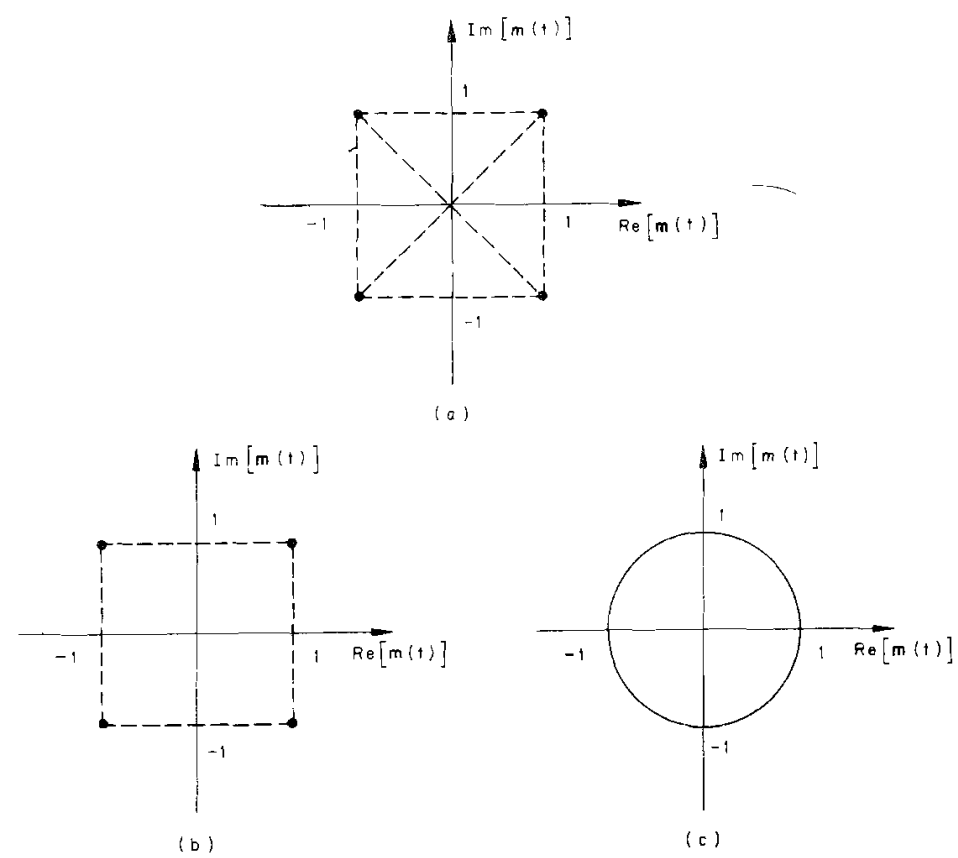

Figura 3. Diagramas das envoltórias complexas dos sinais QPSK (a), OQPSK (b) e MSK (c). As linhas tracejadas indicam transiçōes instantâneas de fase. 
O espectro de potência do sinal QPSK, obtido de (4) e da transformada de Fourier do pulso especificado em (12), é dado por

$$
S_{m}(f)=2 A^{2} T \cdot \operatorname{sinc}^{2}(T f)
$$

onde

$$
\operatorname{sinc}(T f)=\frac{\operatorname{sen}(\pi T f)}{\pi T f}
$$

A largura do lóbulo principal do espectro deste sinal é igual à taxa de bits $(2 / T)$ e o decaimento assintótico dos lóbulos secundários é lento (com †2), o que usualmente leva à necessidade de filtragem do sinal modulado, a fim de acomodá-lo à faixa de freqüências disponivel para transmissão. Uma vez filtrado, o sinal QPSK apresenta variaçōes acentuadas de envoltória, que se anula nas transiçōes de fase de $\pi$ radidanos, e isto $o$ torna bastante susceptível aos efeitos de não linearidade, inclusive à regeneração dos lóbulos espectrais filtrados [11].

Na modulação OQPSK ("Off-Set Quadrature Phase Shift Keying") os pulsos de banda básica são idênticos aos dados por (11), exceto pela introdução de um retardo, igual ao inverso da taxa de bits, no pulso do canal em quadratura. Assim sendo, tem-se

$$
\begin{aligned}
& p_{c}(t)=\operatorname{ret}_{T}(t) \\
& p_{s}(t)=p_{c}\left(t-T_{b}\right)
\end{aligned}
$$

onde $\mathrm{Tb}=\mathrm{T} / 2$.

Devido ao desalinhamento dos pulsos de banda básica, a envoltória do sina OQPSK não apresenta transições instantâneas de fase de $\pi$ radianos, como é mostrado na Fig. 3(b). O espectro de potência é idêntico ao do sinal QPSK. No caso de ser filtrado, apesar de continuar com espectro idêntico ao do QPSK, o sinal OQPSK apresenta envoltória bem mais suave, devido à ausência das transições de fase de $\pi$ radianos. Isto reduz 0 efeito de regeneração espectral das não linearidades [3] e por isso espera-se que a modulação OQPSK produza desempenho superior ao da modulação QPSK, em canais não lineares. 
Uma comparação da eficiência espectral dos sinais OPSK (OQPSK) e MSK com base na fração de potência fora de uma dada faixa pode ser obtida da Fig. 5. As curvas ali mostradas foram obtidas pelo cálculo numérico de (5), usando um algoritmo de transformada rápida de Fourier para obtenção do espectro de ampiitude dos pulsos cie baixa freqüência. Observa-se na Fig-5 a maior eficiência espectral proporcionada pela modulação MSK, quando se considera valores de faixa acima de $1,5 / T$, aproximadamente.

\subsection{MSK Generalizado}

Algumas técnicas de modulação foram propostas a partir da modulação MSK, procurando manter suas características de envoltória constante e de deteção ótima em canal linear com o receptor QAM e ainda obter aumento na eficiência espectral. Note-se que é possivel obter o desempenho ótimo do receptor QAM em canal linear usando filtros casados e pulsos de transmissão limitados no tempo a um intervalo de símbolo.

Mantendo-se as caracterísitcas básicas do sistema MSK, teríamos, para um sinal MSK genérico

$$
\begin{aligned}
& p_{c}(t)=p(t) \\
& p_{s}(t)=p\left(t-T_{b}\right)
\end{aligned}
$$

onde $p(t)$ é um pulso que se anula fora do intervalo $[-T b, T b]$.

A condição para que um sinal QAM-4 cujos pulsos satisfaçam a (19) tenha envoltória constante pode ser obtida de (2) e é dada por

$$
p^{2}(t)+p^{2}\left(t-T_{b}\right)=1, \quad 0 \leqslant t \leqslant T_{b}
$$

Com relação à eficiência de ocupação espectral, uma técnica QAM-4 ótima poderia, em princípio, ser obtida através do critério de minimização da fração de potência fora da faixa, a qual fica definida pelo espectro de amplitude dos pulsos de banda básica, como se vê em (5). É mostrado em [15] que este critério de otimizaçãa conduz à função esferóide prolato. No entanto, esta função sequer é contínua e não satisfaz às condiçōes de generalização do sistema MSK mencionadas acima. Assim, a alternativa mais prática de abordagem deste problema passa a ser a proposição de formas de pulso que, satisfazendo às condiçōes de generalização do sinal MSK, produzam vantagens sobre este no tocante à eficiência espectral [4]-[6] .

1. Assume-se que a largura de faixa do canal é sufliclente para acomodar sem distorçăo, todo o espectro de potência do sinal. 
Jma classe abrangente de sinais do tipo MSK pode ser obtida de maneira semeihante à usada em [5] e [6] definindo-se o pulso o(t) de (19) como

$$
P(t)=\left\{\begin{array}{l}
\cos [\pi q(t)], \quad 0<t \leqslant T_{b} \\
\operatorname{sen}\left[\pi q\left(t+T_{b} \mid\right], \quad-T_{b} \leqslant t<0\right. \\
0, \quad|t|>T_{b}
\end{array}\right.
$$

onde $q(t)$ é uma função contínua e não negativa em $[0, \mathrm{~Tb}]$, com $q(0)=$ 0 e $q(T b)=1 / 2$, o que garante a continuidade da envoltória do sinal. ${ }^{2} E$ possivel mostrar que a condição para que $p(t)$ seja simétrico é dada por

$$
q\left(T_{b}\right)=1 / 2-q\left(T_{b}-t\right)
$$

que implica na condição $q(T b / 2)=1 / 4$.

Observe-se que o sistema MSK propriamente dito corresponde a um caso particular da definição anterior para o qual o pulso $q(t)$ de (21) é dado por

$$
q(t)=\frac{t}{2 T_{b}}, \quad 0 \leqslant t \leqslant T_{b}
$$

Os sinais do tipo MSK definidos por (2), (19) e (21) podem ser considerados como sendo modulados em fase (ou freqüência) e dados por

$$
m(t)=A \cos \left[2 \pi f_{c} t+\sum_{i}\left(\pi d_{i} q\left(t-i T_{b}\right)+\psi_{i}\right)\right]
$$

onde

$$
\begin{gathered}
d_{i}=(-1)^{i} a_{i} a_{i+1} \\
\psi_{i}=\psi_{i-1}+d_{i-1} \frac{\pi}{2}
\end{gathered}
$$

Alguns casos particulares de sinais da classe MSK Generalizado são apresentados em seguida.

2. A relaçăo entre $q(t)$ e o pulso $g(t)$ defininido em [6] \& dada por $q(t)=\left(t / 2 T_{b}\right)$. $g(t)$. A condlçăo (8) da mesma referêncla está embutida na definição (21). 


\section{SFSK}

Na modulação SFSK ("Sinusoidal Frequency Shift Keying"), o pulso q (t) de (21) é definido como

$$
q(t)=\frac{t}{2 T_{b}}-\frac{1}{4 \pi_{b}} \operatorname{sen}\left(\frac{2 \pi t}{T_{b}}, 0 \leqslant t \leqslant T_{b}\right.
$$

Os pulsos de baixa freqüéncia têm derivada contínua nos extremos do interyalo de sinalização, o que significa que a taxa de variação das envoltórias das portadoras em fase e quadratura é contínua, produzindo um rápido decaimento dos lóbulos secundários do espectro [4] . Alternativamente, pode-se observar na expressão (24) que, com a definição dada em (25), as variaçōes de tase da portadora SFSK são mais suaves do que no caso da modulação MSK, uma vez que nesta modulação o pulso q (t) näo tem derivada contínua. Un exemplo desta propriedade é mostrada na Fig.4 onde $\theta$ (t) representa a fase do sinal. A maior suavídade nas variações de fase implica em menor potência nos lóbulos secundários do espectro. Também se vê, de (24) que com o pulso $q(\hat{l})$ dado por (25) a freqüência do sinal modulado varia de forma senoidal em torno do valor $f_{c}$, vindo daí a denominação SFSK.

Não é possivel obter uma expressão analítica simples para o espectro de potência do sinal SFSK. A fração de potência fora de uma dada faixa, calculada numericamente, também é mostrada na Fig. . $_{i}$ onde se observa que o sinal SFSK apresenta menos potêncla fora de faixa que o MSK apenas para valores de faixa acima de 5,7/T, aproximadamente. Estes valores, no entanto, são pouco significativos, devido à reduzida parcela da potência do sinal aí contida.

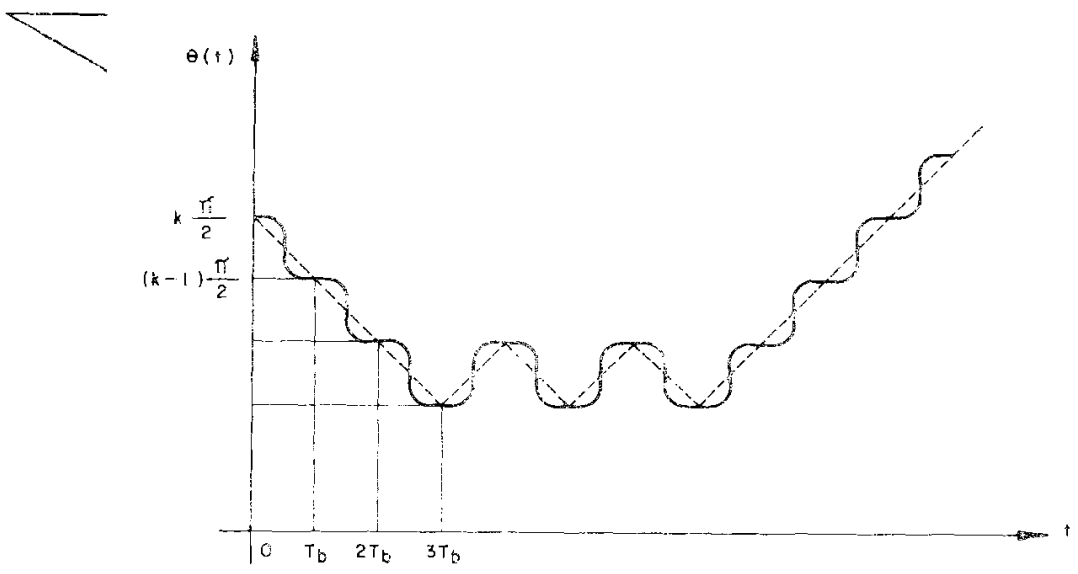

Figura 4. Exemplo típico da variação de fase de sinais com modulação MSK (.....) e SFSK (- 


\section{MSK-RC}

Na modulação MSK-RC ("MSK-Raised Cosine"), o sinal modulado fica definido por

$$
q(t)=\frac{q}{2}\left(1-\cos \frac{\pi t}{T_{b}} ;, 0 \leqslant t \leqslant T_{b}\right.
$$

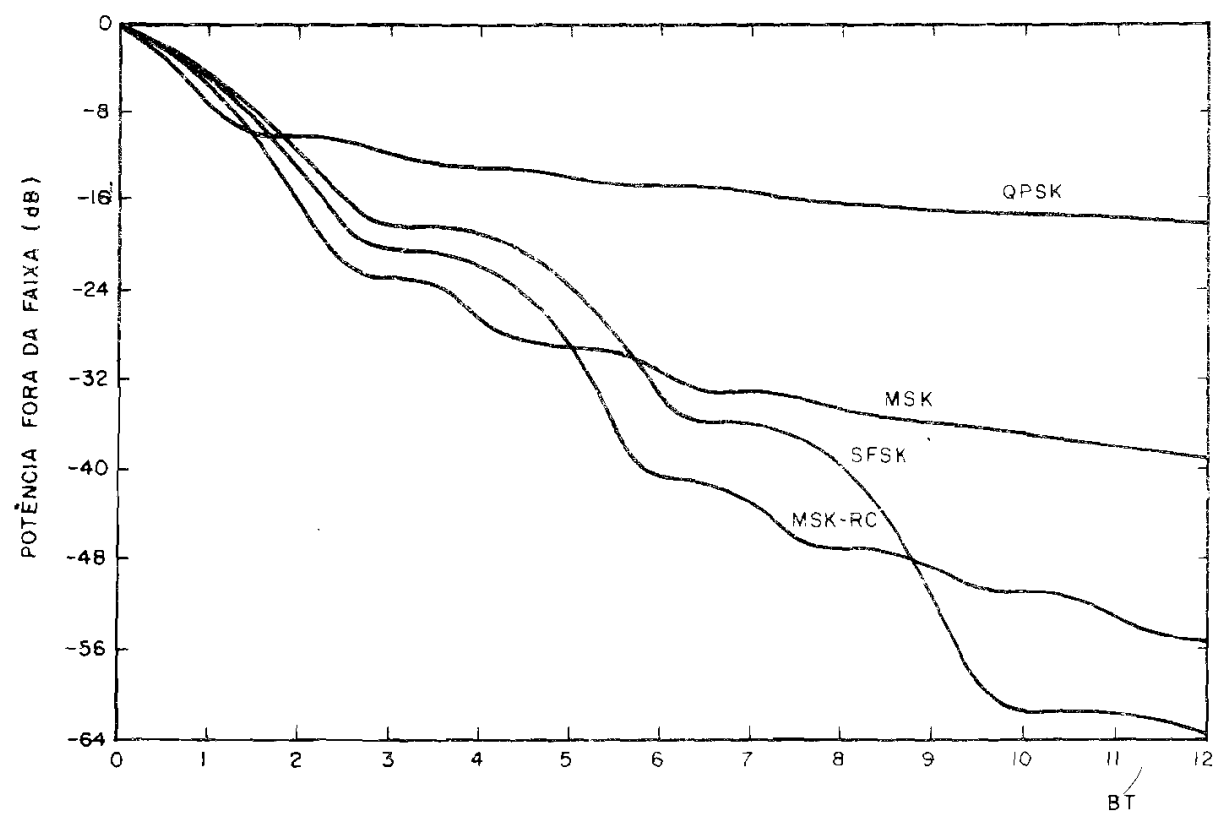

Figura 5. Fração de potência fora de uma faixa de largura $B$, centrada em $t_{C}$, para os sinais QPSK (OQPSK), MSK, SFSK E MSK-RC, calculados numericamente.

Segundo Simon [5], um sinal com modulaçao MSK-RC apresenta decaimento dos lóbulos espectrais secundários maiss rápido que o sinal SFSK. A denominação MSK-RC aqui empregada se deve à forma de cosseno levantado de pulso $q(t)$ em (26).

A expressão analítica do espectro de potência deste sinal não é simples e, para avaliar a sua eficiência especîral, a fração de potência fora de uma dada faixa é calculada numericamente. O resultado, também mostrado na Fig.5, confirma a expectativa de maior eficiência espectrai, relativa. aos sinais SFSK. Quando comparado ao MSK, só se percebe vantagem em valores de faixa acima de 5/T, aproximadamente. 


\section{MSK-RP}

Zazbei e Pasupathy apresentam em [6] uma lamilla de pulsos do tipo MSK, caracterizada por

$$
q(t)=h(t, n, M)=\frac{t}{2 T_{b}}\left\{1-\frac{\sum_{=1}^{M} K_{i}\left[\operatorname{sen}\left(n \frac{2 \pi t}{T_{b}}\right)\right]^{2 i-1}}{n \frac{2 \pi t}{T_{b}}}\right\}
$$

onde $n=1,2,3 \ldots ; M=0,1,2, \ldots e$

$$
K_{i}=\frac{(2 i-2) !}{2^{2 i-2}[(i-1) !]^{2}(2 i-1) !}
$$

Com esta definição, o pulso $p(t)$ dado por (21) tem derivada contínua até a ordem $2 \mathrm{M}$ e, em conseqüência, o espectro de potência do sinal definido através de (2) e (19) decaiassintoticamente com $f^{4 M * 4}$.O sinal MSK corresponde ao caso articular onde $q(t)=h(t, n, 0)$, resultando num decaimento assintótico do espectro com $f^{4}$, enquanto o SFSK corresponde a $q(t)=h(i, 1,1)$, o que leva a um decaimento assintótico do espectro com $f^{8}$.

O aumento do parâmetro $M$ reduz a fração de potência fora de uma dada faixa somente para valores elevados da largura de faixa. A reduçăo de potência fora de uma dada faixa para valores pequenos da largura de faixa pode ser obtida com valores mais elevados do parâmetro $n$, segundo o que se afirma em [6]. No entanto, não é definida nesta referência nenhuma forma particular de pulso que se constitua em alternativa às apresentadas em outros trabalhos.

A generalização do sistema MSK descrita nesta seçāo possui limitaçōes dignas de observação. Uma delas é que a redução da potência fora de uma dada faixa, relativa à modulação $M S K$, só se verifica para valores elevados da faixa de frequências. Além disso, como se afirma em [17], a largura do lóbulo principal do espectro é sempre maior que a do QPSK (OQPSK), o que pode ser uma desvantagem séria para transmissão em

3. Dal a denominação MSK-RP empregada acima.

38 
canal de faixa estreita. Por fim, sob as condiçōes dadas em (19) e (20), a modulação MSK propriamente dita é quase ótima no sentido de minimizar a potência fora de uma dada faixa para valores reduzidos de faixa [18], o que torna menos significativa a generalização comentada acima.

\subsection{Técnicas QAM-4 com Envoltória Variável}

A eficiência espectral obtida com as técnicas de modulação descritas acima é muitas vezes insuficiente para dispensar o uso de filtros limitadores de faixa na transmissão. Esta filtragem modifica a forma dos pulsos de baixa freqüência e produz urn sinal com envoltória variável, o qual pode ser muito susceptivel aos efeitos de não linearidades no canal. Assim sendo, faz sentido o relaxamento da condição de envoltória constante ao se investigar técnicas QAM-4 alternativas, procurando obter com isto ganhos significativos em eficiência espectral. Em seguida são apresentadas algumas destas técnicas, onde a duração dos pulsos de baixa frequeência é maior que o intervalo correspondente a um símbolo e se admite alguma variação na envoltória do sinal modulado.

\section{SQAM-Sinc}

Em [7] define-se uma classe de sinais QAM-4, pelas relaçōes

$$
\begin{aligned}
& p_{c}(t)=[\operatorname{sinc}(t / T)]^{n} \operatorname{ret}_{2 T}(t) \\
& p_{s}(t)=p_{c}(t-T / 2)
\end{aligned}
$$

onde o parâmetro $n$ é um inteiro não nulo. Esta classe de sinais é aqui denominada SQAM-Sinc ("Staggered QAM-Sinc"), devido ao uso da função sinc (o) na definição dos pulsos.

Neste caso, a duração dos pulsos é maior que o intervalo correspondente a um símbolo. Em princípio, não é gerada interferência entre símbolos nos instantes em que estes pulsos têm amplitude máxima. No entanto haverá interferência entre simbolos no sinal filtrado, mesmo que o filtro seja casado. É usado o desalinhamento entre os pulsos de baixa freqüência a fim de reduzir as variaçōes na envoltória. $\mathrm{Na}$ referência [7] sugere-se o emprego de um limitador abrupto ("hard limiter") na modulação SQAM-Sinc a fim de produzir um sinal com envoltória constante, especulando-se que, apesar 
do espalhamento espectral provocado pelo limitador, a eficiência resultante seria compensadora, especialmente para valores pequenos da faixa de freqüências.

No que concerne ao parâmetro n em (28), os resultados apresentados em [7] indicam que, aumentando-se o seu valor, a compactaçăo do espectro do sina! modulado (sem passar pelo limitador) é maior, mas, por outro lado, o espalhamento produzido pelo limitador também o é. Na Fig.6 são mostradas curvas de fraçāo de potência fora de uma dada faixa para sinais SQAM-Sinc, sem e com o uso do limitador ideal, e para valores de $n$ até 3 . Essas curvas também foram obtidas numericamente. $O$ processo de cálculo das curvas correspondentes ao uso do limitador, baseado em [19], é descrito em $[20]$.

\section{QORC (OU IJF-QPSK)}

Na modulação QORC ("Quadrature Overlapped Raised Cosine") [8], também denominada IJF ("Intersymboi Interference and Jitter Free") -QPSK [9]. os pulsos de baixa freqüência são definidos como

$$
p_{c}(t)=p_{s}(t)=\frac{1}{2}\left(1+\cos \frac{\pi t}{T}\right) \operatorname{ret}_{2 T}(t)
$$

Como no caso anterior, estes pulsos têm duração igual ao intervalo correspondente a dois símbolos mas não gerada interferência entre símbolos nos instantes correspondentes à amplitude máxima dos pulsos. O diagrama da envoltória complexa do sinal modulado, cujo módulo é variável, é mostrado na Fig. 7(a). Observe-se a semelhança com o diagrama do QPSK mostrado na Fig.3(a). De fato, o sinal QORC pode ser visto como um sinal QPSK convenientemente filtrado.

O espectro de potência do sinal pode ser obtido facilmente observando os pulsos definidos em (29) como resultantes da convolução de um pulso retangular com um oulso senoidal, ambos com duração $T[8]$. A expressão obtida é

$$
\left.B_{n} f\right)=\frac{3 A^{2} T^{2}}{\pi^{2}} \operatorname{sinc}^{3}\left(h-\frac{t \cos 2 \pi T \hat{~}}{\left.i-4 T^{2} f^{2}\right\}^{2}}\right.
$$



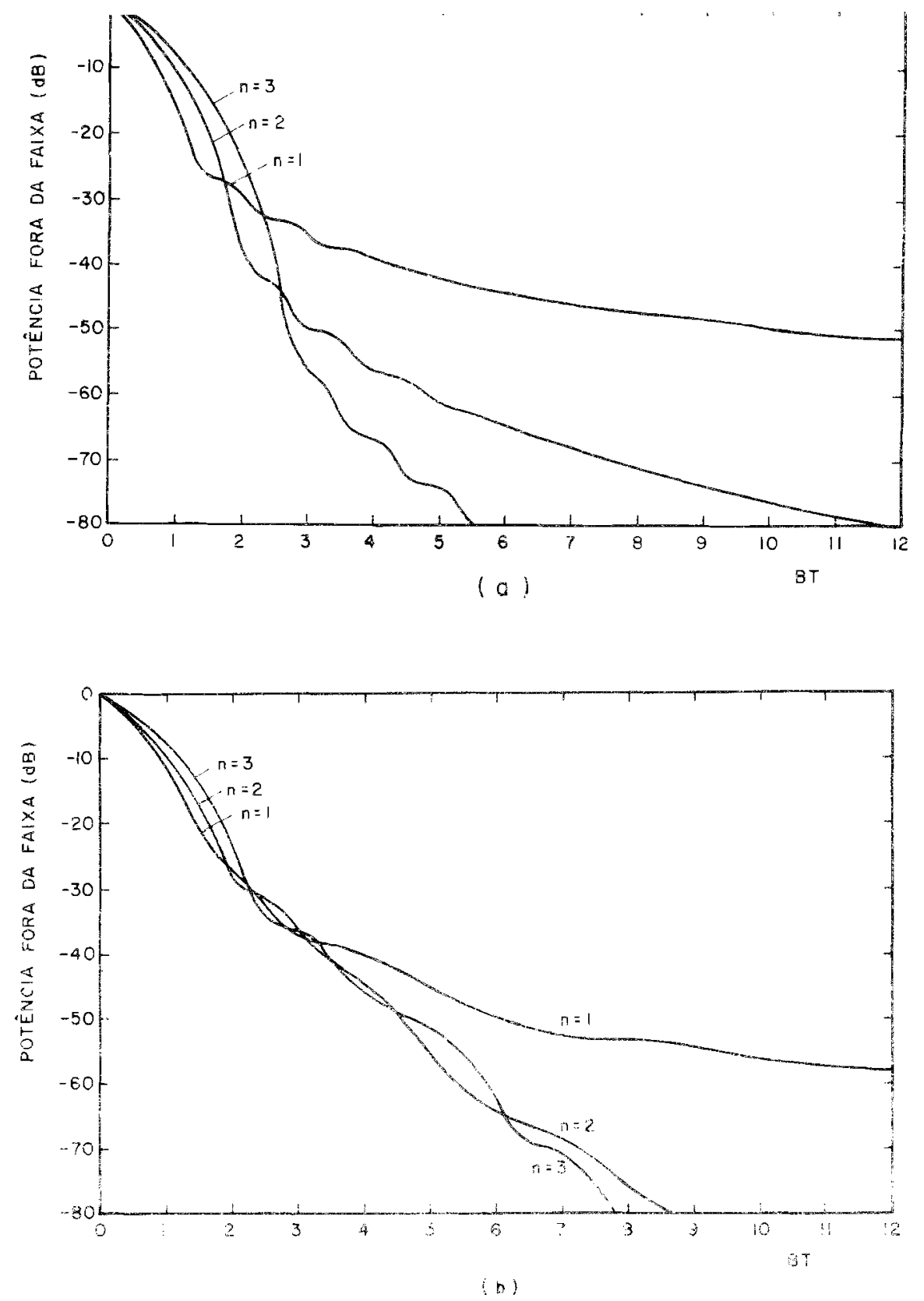

Figura 6. Fração de potência lora de uma dada laixa para sinais soAM-sinc, com diversos vaiores do parânetron n. (a) shal modulado sem imitador; to sinal modulado, seguido de limilador ideal.

Aevista da Sociedade Brasileira de Telecomunicações 
e corresponde, a menos de uma constante, ao produto dos espectros das envoltórias QPSK e MSK. A largura do lóbulo principal é igual à do espectro da envoltória OPSK e ao mesmo tempo o decaimento assintótico dos ióbulos secundários é bem mais rápido (com $\left.f^{6}\right)$. Portanto, no que se refere às propriedades espectrais, o QORC combina as vantagens dos sinais QPSK e MSK. Porén, no que tange à envoltória jáa năo se pode dizer o mesmo.

\section{SQORC (OU IJF-OQPSK)}

A formatação de pulsos na modulação SQORC ("Staggered QORC") [8] , também denominada IJF-OQPSK [9], é idêntica à da modulação QORC, a menos do deslocamento de T/2 nos pulsos do canal em quadratura.

A envoltória do sinal SQORC apresenta variações inais suaves, devido à inexistência de transições de fase de $\pi$ radianos, e é mostrada naFig.7(b). Observe-se nas figuras 7(b), 3(b) e 3(c) que o diagrama da envoltória SQORC pode ser interpretado como uma combinação dos diagramas correspondentes às envoltórias OQPSK e MSK.

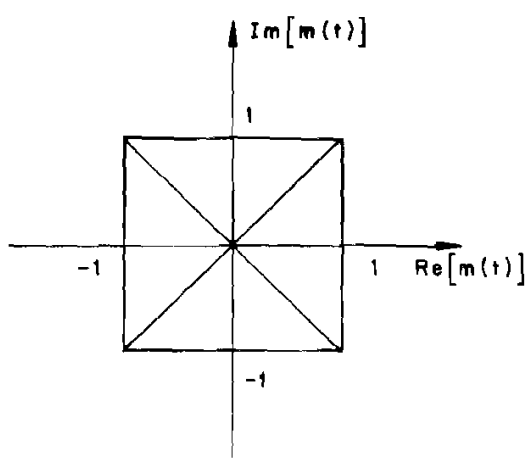

(a)

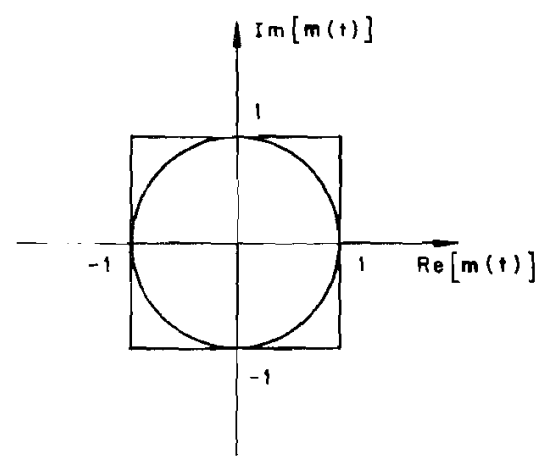

(b)

Figura 7.Diagrama das envoltórias complexas dos sinais QORC (a) e SQORC (b).

O espectro de potência do sinal SQORC é idêntico ao do sinal QORC e dado por (29). Devido à maior suavidade de sua envoltória, o sinal SQORC apresenta menor sensibilidade do que o sinal QORC ao efeito de espalhamento espectral produzido pelas não linearidades [8]. 


\section{TSI-OQPSK}

Em [10] apresenta-se uma classe de técnicas QAM-4 denominada TSI ("Two Symbol Interval") - OQPSK, a qual é definida por

$$
\begin{gathered}
p_{c}(t)=\frac{1}{2}\left\{1-\frac{\operatorname{sen}[\pi(! t \mid-T / 2) / n T]}{\operatorname{sen}(\pi / 2 n)}\right\} \operatorname{ret}_{2 T}(t) \\
p_{S}(t)=p_{C}(t-T / 2)
\end{gathered}
$$

onde o parâmetro $n$ é um número inteiro não nulo. Esta classe de sinais representa uma generalização da modulação SQORC (ou IJF - OQPSK), a qual é obtida com $n=1 \mathrm{em}$ (31). Em [10] faz-se uma avaliação das possibilidades de compactação do espectro e de redução nas variações de envoltória oferecidas por esta classe de pulsos e é mostrado que a modulação SQORC apresenta melhores características que as outras. Na Fig. 8 são apresentadas curvas da potência fora de uma dada faixa para sinais TSIOQPSK, considerando o parâmetro $n$ igual a 1,2 e 3 . Observa-se que a

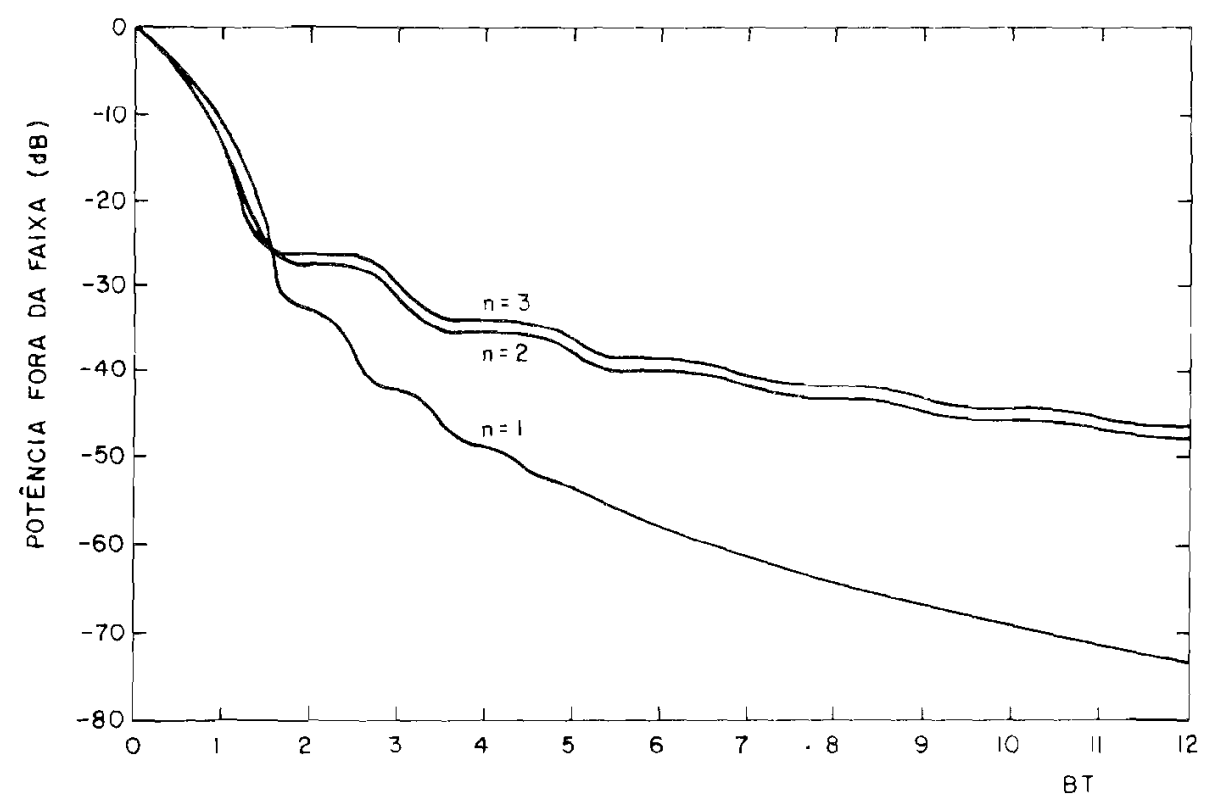

Figura 8. Fração de potência fora de uma dada faixa para sinais TSI-OQPSK, com diversos valores do parâmetro $\mathrm{n}$. 
eficiência espectral do SQORC $(n=1)$ é ligeiramente inferior à dos sinais com $n=2$ e $n=3$, somente quando se considera valores de faixa menores que $1,5 / \mathrm{T}$, aproximadamente. Nos demais valores de faixa a eficiência do SQORC é superior.

\section{Comentários}

As técnicas de modulação QAM-4 apresentadas na Seção 4 correspondem a diferentes tentativas de obter sinais modulados com pouca variação de envoltória e elevada eficiência espectral, mantendo a estrutura básica da modulação QAM-4, a qual oferece grandes vantagens em termos de simplicidade de implementação. Foi feita uma avaliação das potencialidades destas técnicas através da análise da envoltória complexa e da função de potência fora de uma dada faixa para cada tioo de sinal modulado. Os resultados indicam que algumas técnicas QAM-4 podem se constituir em alternativas bastante vantajosas para aplicaçôes em canais não lineares, tendo em vista que produzem sinais cujo espectro decai mais rapidamente com a freqüência do que o espectro de um sinal QPSK e também porque a envoltória destes sinais, mesmo quando filtrados, apresenta variações menores que as variações da envoltória de um sinal QPSK filtrado.

Uma avaliação mais precisa da melhoria de desempenho que se pode obter com estas ténicas requer a definição específica do sistema de iransmissão, - que implica, entre outras coisas, na definição dos filtros de transmissão e recepção, dos filtros de canal, das não linearidades e dos sinais interferentes. Há uma garna muito vasta de alternativas a se considerar e geraimente se usa a simulação em computador como instrumento para avaliação de desempenho.

Diversos trabalhos recentes apresentam resultados de simulação das técnicas QAM-4 aqui apresentadas [3], [8], [11] e [21] - [27]. Um sumário dos resultados destes trabalhos está contido em [20], onde se observa a dificuldade de comparar a eficiência das diversas técnicas a partir destes resultados, devido às diferenças entre os modelos do sistema de transmissão empregados. Em linhas gerais, o que se conclui é que a melhoria de desempenino produzida por algumas técnicas em relaçăo à modulação QPSK só é significativa quando se inclui no modelo do sistema a interierencia de portadoras adjacentes.

Em [20] também é feita uma avaliação sistemática de todas as técnicas QAM-4 mencionadas na Seção 4, simulando em computador modelos típicos de transmissão sem $\mathrm{Q}$ com interferência de canais adjacentes. Os resuitados obtidos usando um modelo de sistema de transmissăo no qual há interferência de canais adjacentes após a passagem dos sinais por um amplificador não 
linear indicam que algumas técnicas QAM alternativas podem produzir ganhos significativos de desempenho em relação à modulação QPSK. Em particular, quando $o$ afastamento na freqüência entre o canal de interesse e dois canais adjacentes (com mesmo tipo de modulação, taxa de trasmissão e nível de potência) é da ordem de $1,6 / T$, as técnicas OQPSK (com illtros do tipo raiz quadrada de cosseno levantado no transmissor e receptor) e SQAM-Sinc (com parâmetro igual a 3 e com filtro de Butterworth de $7 .{ }^{.}$ordem no receptor) produzem uma melhoria superior a $3,0 \mathrm{~dB}$ na razão $E_{b} / N_{0}$ necessária para se obter uma taxa de erro de bits igual a $10^{-4}$, em relação à modulação QPSK com filtros do tipo raiz quadrada de cosseno levantado. Esta melhoria da ordem de $6,0 \mathrm{~dB}$ quando se requer uma taxa de erro de bits igual a $10^{-6}$. Deve-se afirmar que nas comparações de desempenho apresentadas am [20] ,os parâmetros de definição dos filtros de transmissão e recepção sảo otimizados, no sentido da minimizaçāo da taxa de erro, para cada valor do alastamento entre o canal de interesse e os canais interferentes. Em [20] ainda são apresentados resultados referentes à ocorrêncla de desvanecimento do canal principal, os quais ressaltam o significado da maior imunidade às interferências de canais adjacentes que se obtém usando técnicas de modulação alternativas à modulação QPSK. Esta discussão detalhada do desempenho das modulações QPSK e OQPSK com filtros de transmissäo e recepção do tipo raiz quadrada de cosseno levantado, em diferentes condições de transmissão, é apresentada em [28].

A simulação computacional confirma, portanto, as indicaçōes do presente trabalho no sentido de se obter desempenho superior ao da modulação QPSK em canais não lineares usando técnicas QAM quaternárias que produzam maior eficiência na ocupação espectral e menor variação na envoltória do sinal modulado.

\section{Referências}

[1] V.K. Bhargava, D. Haccoun, R. Matyas e P.P. Nuspl, "Digital Communisations by Satellite", John Wiley and Sons, 1981.

[2] R. Lucky, J. Salz e E. Woldon, "Principles of Data Communications", McGraw-Hill, 1968.

[3] S. Gronemeyer e A. MCBride, "MSK and Off-Sel QPSK Modulation", IEEE Bransactions on Communications, vol. COM-24, n. $8, A$ gosto 1976, วp. $309-820$.

4.] F. Amoroso, "Pulse and Spectrum Manipulation in the Minimum (Frequency) Shifit Keying (MSK) Fomat", IEEE Transactions on Communications, yol. COM-24, n. 3, Março 1976, pp. 381-384. 
[5] M. K. Simon, "A Generalization of Minimum-Shift-Keying (MSK) Type Signaling Based Upon Input Data Symbol Pulse Shaping", IEEE Transactions on Communications, vol. COM-24, n. ${ }^{\circ}$, Agosto 1976, pp. 845-856.

[6] M. Razbel e S. Pasupathy, "Spectral Shaping in Mininum Shift Keying (MSK) - Type Signais", IEEETransactions on Communications, vol. COM-26, n. ${ }^{\circ}$, Janeiro 1978, pp. 189-195.

[7] F. Amoroso, "The Use of Quasi-Bandlimited Pulses in MSK Transmission", IEEE Transactions on Communications, vol. COM-27, $n .{ }^{\circ} 10$, Outubro 1970, pp. 1616-1624.

[8] M. Austin e M. Chang, "Quadrature Overlapped Raised-Cosine Modulation", IEEE Transactions on Communications, vol. COM-29, n.3, Março 1981, pp. 237-249.

[9] T. Le-Ngoc e K. Feher, "Power and Bandwidth Efficient ISI and Jitter Free (IJF) Transmission Techniques for Linear and Nonlinear Channeis", IEEE International Conference on Communications, Denver, Estados Unidos, Junho 1981, pp. 33. 4.1-33.4.5.

[10] H. P. Van e K. Feher, "A Class of Two-Symbol-Interval Modems for Nonlinear Radio Systems", IEEE Transactions on Communications, vol: COM-31, n. 3, Março 1986, pp. 433-441.

[11] R. J. Fang, "Quaternary Transmission over Satellite Channels with Cascaded Nonlinear Elements and Adjacent. Channel Interference", IEEE Transactions on Communications, vol. COM-29, n. ${ }^{\circ}$, Maio 1981, pp. 567-581.

[12] J. G. Proakis, "Digital Communications", McGraw-Hill, 1983.

[13] S. Pasupathy, "Minimum Shift Keying: A Spectrally Efficient Modulation", IEEE Communications Magazine, vol. 17, n.० 4, Julho 1979, pp. 14-22.

[14] S. Haykin, "Communication Systems", John Wiley \& Sons, Inc., 1978.

[15] R. De Buda, "Coherent Demodulation of Frequency Shift Keying With Low Deviation Ratio", IEEE. Transactions on Communications, vol. COM-20, n. 3 , Junho 1972, pp. 429-435.

[16] V. K.Prabhu, "Spectral Occupancy of Digital Angle-Modulation Signals", The Bell System Technical Journal, vol. 55, n. 4, Abril 1976, pp. 429-452.

[17] N. Boutin e S. Morissette, "Do All MSK-Type Signaling Waveforms 
Have Wider Spectra Than Those for PSK?", IEEE Transactions on Communications, vol. COM-29, n. ${ }^{\circ}$, Julho 1981, pp. 1071-1072.

[18] G. Desphande e P. Wittke, "Optimum Pulse Shaping in Digital Angle Modulation", IEEE Transactions on Communications, vol. COM-29, n. 2, Fevereiro 1981, pp. 162-168.

[19] D. Divsalar e M. K. Simon, "The Power Spectral Density of Digital Modulations Transmitted over Nonlinear Channels", IEEE Transactions on Communications, vol. COM-30, n. 1 , Janeiro 1982, pp. 142-151.

[20] E. L. Pinto, "Desempenho de Sistemas QAM Quaternários em Canais Não Lineares", Dissertação de Mestrado, Departamento de Engenharia Elétrica, PUC/Rio, Agosto 1986.

[21] M. C. Austin, M. U. Chang, D.F. Horwood e R.A Maslov, "QPSK, Staggered QPSK and MSK-A Comparative Evaluation", IEEE Transactions on Communications, vol. COM-31, n.. 2, Fevereiro 1983, pp. 171-182.

[22] D. Morais e K. Feher, "The Effects of Filtering and Limiting on the Performance of QPSK, Offset QPSK and MSK Systems", IEEE Transactions on Communications, vol. COM-28, n.. 12, Dezembro 1980, pp. 1999-2009.

[23] T. Le-Ngoc, K. Feher e H. P. Van, "New Modulation Techniques for Low-Cost Power and Bandwidth Efficient Satellite Earth Stations", IEEE Transactions on Communications, vol. COM-30, n. 1 , Janeiro 1982, pp. 275-283.

[24] T. Le-Ngoc e K. Feher, "A New Class of IJF-OQPSK Modems for Regenerative Satellite Systems", IEEE International Conference on Communications, Denver, Estados Unidos, Junho 1981, pp. 37.5.1 - 37.5.6.

[25] S. Murakami, Y. Furuya, Y. Matsuo e M. Sugiyama, "Optimum Modulation and Channel Filters, for Nonlinear Satellite Channels", IEEE Transactions on Communications, vol. COM-27, n.*12, Dezembro 1979, pp. 1810-1819.

[26] T. Le-Ngoc e K. Feher, "Performance of IJF-OQPSK Modulation Schemes in the Presence of Noise, Interchannel and Cochannel Interference", IEEE National Telecommunications Conference, New Orleans, Estados Unidos, 1981, pp. B.7.6.1 - B.7.6.5.

[27] H. P. Van e K. Feher,"TSI-OQPSK for Multiple Carrier Satellite Systems", IEEE Transactions on Communications, vol. COM-32, n. 7 , Julho 1984, pp. 818-825. 
[28] E. L. Pinto e J. C. Brandão, "Desempenho de Sistemas PSK-4 com Filtros de Nyquist em Presença de Não Linearidade e Interferência", Anais do V Simpósio Brasileiro de Telecomunicações, Campinas, São Paulo, Setembro 1987, pp. 373-378.

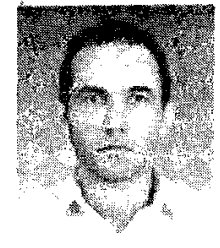

ERNESTO LEITE PINTO nasceu em Itaporanga, Paraíba, em 11 de dezembro de 1960 . Formou-se em Engenharia Elétrica pela Universidade Federal da Pararba, Campina Grande, em 1983 e obteve o grau de Mestre em Ciências em Engenharia Elétrica na PUC/Rio, em 1986. Durante o programa de mestrado realizou estudos sobre técnicas de modulaçăo aplicáveis em comunicaçōes via sa télite, com suporte financeiro da TELEBRÁS. É desde 1987 Professor Assistente no Instituto Militar de Engenharia. Seus interesses de pesquisa incluem a simulação da transmissão digital e o estudo de técnicas avançadas de modulação. Ernesto L. Pinto é membro da Sociedade Brasileira de Telecomunicações.

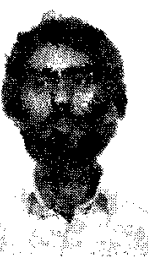

JOÃO CÉLIO B. BRANDÃO naceu em Santo Antônio do Grama, Minas Gerais, em 23 de fevereiro de 1947. Formou-se em Engenharia Elétrica pela Universidade Federal de Juiz de Fora em 1969 e obteve o grau de Mestre em Ciências em Engenharia Elétrica na PUC/Rio, em 1973. Desde 1973 é Professor no Centro de Estudos em Telecomunicações (CETUC) da PUC/Rio. De 1977 a 1978 trabalhou no COMSAT Laboratories, Maryland, Estados Unidos, dentro do INTELSAT Assignee Program. De 1979 a 1982 foi Vice-Diretor do CETUC. Desde 1974 realiza pesquisas dentro de contrato existente entre a PUC/Rio e a TELEBRÁS. Suas áreas principais de interesse são a análise e a simulação de sistemas de transmissão digital. 